\title{
ANALISIS INVESTASI KAPAL DRY-BULK CARRIER DENGAN MENGGUNAKAN SISTEM DINAMIK
}

\author{
Dian Pratiwi Sahar \\ Jurusan Teknik Industri, Fakultas Teknik, Universitas Pattimura \\ dian.sahar@fatek.unpatti.ac.id \\ Mohammad Thezar Afifudin \\ Jurusan Teknik Industri, Fakultas Teknik, Universitas Pattimura \\ thezar.afifudin@fatek.unpatti.ac.id \\ A. Besse Riyani Indah \\ Departemen Teknik Industri, Universitas Hasanuddin \\ a.besseriyani@gmail.com
}

\begin{abstract}
ABSTRAK
Peningkatan demand semen curah di Kawasan Timur Indonesia mendorong perusahaan untuk meningkatkan kapasitas produksinya. Hal ini menyebabkan perusahaan perlu menambah kapasitas transportasinya agar semua demand di Packing Plant dapat dipenuhi. Sehingga tujuan dari penelitian ini adalah menentukan jenis investasi kapal yang dapat memberikan profit terbesar bagi perusahaan. Semen didistribusikan dalam bentuk curah dengan menggunakan kapal dry-bulk carrier. Kapal yang digunakan terdiri dari dua jenis, yaitu berdasarkan kapasitasnya (volume muat) dan berdasarkan investasinya. Terdapat 7 (tujuh) jenis kapal berdasarkan kapasitasnya, yaitu: kapal kapasitas 1.000 ton; 3.000 ton; 4.000 ton; 5.000 ton; 6.000 ton; 8.000 ton; dan 12.000 ton. Sedangkan jenis kapal berdasarkan investasinya terdiri dari tiga, yaitu bareboat charter, time charter, dan freight based. Kapasitas kapal dry-bulk carrier harus dapat memenuhi order size Packing Plant tujuan sebelum kapasitas silo Packing Plant mencapai titik safety stock. Akan tetapi, kapasitas kapal yang digunakan harus memenuhi syarat draught pelabuhan masing-masing Packing Plant. Pemodelan dengan sistem dinamik digunakan untuk menyelesaikan permasalahan keputusan investasi kapal. Dari hasil running simulasi diperoleh jenis investasi yang memberikan profit terbesar, yaitu investasi dilakukan dengan sistem freight charter dengan vendor. Investasi kapal ini dapat meningkatkan profit perusahaan sebesar $2.20 \%$. Jenis kapal yang disewa adalah kapal berkapasitas 12.000 ton sebanyak 1 (satu) unit.
\end{abstract}

Kata kunci: investasi kapal, sistem dinamik, freight charter, reorder point

\section{ABSTRACT}

The increasing demand for bulk cement in Eastern Indonesia has encouraged companies to increase their production capacity. This causes the company to increase its transportation capacity so that all demands in the Packing Plant can be met. So that the purpose of this study is to determine the type of ship investment that can provide the largest profit for the company. Cement is distributed in bulk using drybulk carrier. There are two types of ships used, namely based on capacity (volume) and investment. There are 7 (seven) types of ships based on their capacity, that is: ships with a capacity of 1,000 tons; 3,000 tons; 4,000 tons; 5,000 tons; 6,000 tons; 8,000 tons; and 12,000 tons. Meanwhile, there are three types of ships investment, namely bareboat charter, time charter and freight based. The dry-bulk carrier capacity must meet the destination Packing Plant order size before the silo Packing Plant capacity reaches the safety stock point. However, the ship capacity used must meet the port draft requirements of each Packing Plant. Dynamic system modeling is used to solve ship investment decision problems. From the results of running simulations, it is found that the type of investment that gives the biggest profit is that the investment is carried out using a freight charter system with a vendor. This ship investment can increase the company's profit by 2.20\%. The types of ships charted are 1 (one) unit capacity 12,000 tonnes.

Keywords: ship investment, dynamic system, freight charter, reorder point 


\section{PENDAHULUAN}

Tahun 2013 kapasitas produksi semen meningkat sebesar $25.42 \%$ dari tahun sebelumnya (Tonasa, 2014). Peningkatan kapasitas produksi pada tahun 2013 menyebabkan perusahaan perlu mempertimbangkan penambahan armada pengangkutan semen demi kelancaran pendistribusian semen.

Semen didistribusikan dalam bentuk semen sak dan semen curah. Moda yang digunakan dalam proses distribusi adalah truk dan kapal. Truk digunakan untuk mengangkut semen sak dari pabrik ke beberapa distributor yang berada di Sulawesi Selatan, sedangkan kapal digunakan untuk mengangkut semen antar pulau. Semen curah diangkut dari pabrik ke Silo Pelabuhan dengan menggunakan truk curah (trailer). Selanjutnya semen akan didistribusikan dengan kapal dry-bulk carrier ke beberapa Packing Plant (PP) yang terletak di Kawasan Timur Indonesia. Kapal dry-bulk carrier digunakan karena kelebihannya dalam memuat dengan jumlah yang lebih besar dengan biaya yang lebih murah.

Investasi kapal dry-bulk carrier perusahaan terdiri dari tiga jenis, bareboat charter, time charter, dan freight based. Kapal yang digunakan dipilih harus memenuhi ketentuan seperti ukuran (dimensi), kecepatan tempuh (laju), dan biaya pengadaan (investasi). Analisis investasi kapal pernah dibahas oleh beberapa penelitian terdahulu, seperti Jin (2008) menggunakan pendekatan sistem dinamik; Fan dan Luo (2013) menggunakan binary choise and nested logit model; dan PARK, et. al. (2014) menggunakan sistem dinamik.

Sistem dinamik digunakan sebagai metodologi pada penelitian ini karena dapat menyelesaikan masalah sistem yang kompleks (Sterman, 2000). Salah satu karakteristiknya adalah adanya sistem umpan balik tertutup (loop feedback). Metodologi ini pernah digunakan pada bidang manufaktur (e.g. Georgiandis, 2013; Anggraeni dan Suryani, 2013, Fortunella et. al., 2012). Penelitian ini akan menggunakan sistem dinamik untuk menganalisis keputusan investasi kapal yang akan dilakukan seiring dengan peningkatan kapasitas produksi (production) di pabrik dan permintaan (demand) di Packing Plant.

\section{LANDASAN TEORI \\ Penyewaan Kapal}

Steffensen (2012) mengelompokkan jenis-jenis kontrak sewa kapal menjadi bareboat charter, time charter, dan freight based. Sewa kapal biasanya dilakukan dalam rentang waktu yang cukup panjang, jadi sebaiknya dilakukan analisis yang mendalam sebelum memutuskan jenis sewa kapal yang akan digunakan. Beberapa aspek yang dipertimbangkan seperti jenis muatan, rute, durasi sewa, dan biaya (sewa kapal maupun biaya yang harus dikeluarkan selama masa sewa berlangsung).

Bareboat charter dilakukan dengan cara penyewaan kapal tanpa nahkoda dan awak kapal, tetapi kapal dilengkapi dengan sarana dan peralatan selama kapal berlayar. Jenis kontrak ini dapat menguntungkan penyewa kapal karena dapat mengatur operasional dan finansial selama kapal beroperasi. Akan tetapi, penyewa juga harus mengeluarkan biaya-biaya seperti: biaya navigasi, biaya manajemen, biaya maintenance, dan biaya survei kapal.

Time charter dilakukan dengan cara penyewaan kapal berdasarkan waktu (lama) sewa kapal. Keuntungan sewa kapal ini adalah penyewa dapat mengangkut muatan dalam jumlah besar dan dapat mengatur rute kapal berlayar. Pemilik kapal menanggung biaya depresiasi, nahkoda dan awak kapal, maintenance, perbekalan, asuransi, dan overhead. Sedangkan penyewa kapal menanggung biaya sewa, BBM, pelabuhan, Stevedoring, dan Cargodoring (Sasmito, 2014).

Freight charter dilakukan dengan cara penyewaan kapal berdasarkan jenis muatan dan rute pelayaran kapal. Pemilik kapal menanggung biaya nahkoda dan awak kapal maupun biaya sarana dan prasarana selama berlayar sesuai dengan kontrak yang telah dilakukan dengan penyewa kapal dalam melakukan pelayaran per trayek. Jadi penyewa kapal menggunakan seluruh atau sebagian ruang kapal dalam mengangkut muatannya. Biaya sewa biasanya digitung per perjalanan pelayaran.

\section{Sistem Dinamik}

Model sistem dinamik memiliki karakteristik berupa sistem kompleks yang perubahan periku sistemnya berubah terhadap waktu. Terdapat dua pendekatan dalam membangun model sistem dinamik, yaitu top down dan bottom up. Sistem yang dibangun dalam penelitian ini menggunakan pendekatan top down.

Pemodelan sistem dinamik merupakan salah satu metode yang dapat digunakan untuk menggambarkan secara visual model sistem dinamik. Terdapat beberapa tools yang dapat digunakan untuk membangun model, seperti: Stock, Flow, Converter, dan Connector. Hubungan antar tools dapat dilihat pada gambar berikut: 


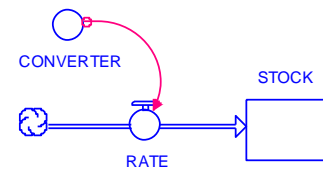

Hubungan Beberapa Tools

Pada penyusunan model simulasi, model dibangun dengan mengetahui hubungan antar variabel terhadap waktu yang digambarkan dalam Stock and flow diagram. Selanjutnya formulasi model matematis dimasukkan ke dalam sistem. Sehingga model dapat running untuk mennjukkan kondisi eksisting dari sistem yang dibangun.

Sistem dinamik telah banyak digunakan untuk menyelesaikan masalah-masalah kompleks di bidang industri, seperti Georgiadis (2013) pada industri daur ulang kertas, Anggraeni dan Suryani (2013) pada industri pupuk, dan Fortunella, et. al. (2012) pada industri kulit. Sistem dinamik membantu decision maker dalam menentukan perencanaan kapasitas produksi pabrik. Sedangkan pada penelitian ini, sistem dinamik digunakan untuk mengetahui perencanaan investasi kapal dengan mempertimbangkan kapasitas produksi dan demand yang mengalami perubahan secara dinamis.

\section{METODOLOGI PENELITIAN}

Tahap awal dari penelitian ini adalah melakukan in-dept interview dengan pimpinan Departeman Distribusi. Data dan beberapa literatur pendukung diperoleh dari laporan tahunan perusahaan. Berdasarkan sumber-sumber tersebut, model simulasi dibangun dengan menggunakan Software Stella.

Tahun 2013 terjadi peningkatan kapasitas produksi semen setelah pembangunan pabrik baru selesai, yaitu sebesar $25,42 \%$ dari tahun sebelumnya. Hal ini sejalan dengan meningkatnya demand di Packing Plant Kawasan Timur Indonesia. Salah satu dampak yang ditimbulkan dari situasi ini adalah proses distribusi semen. Sehingga diperlukan penambahan armada baru untuk mengangkut hasil produksi semen ke masing-masing Packing Plant.

Kapal dry-bulk carrier digunakan untuk mendistribusikan semen dalam bentuk curah. Investasi kapal dry-bulk carrier dapat dilakukan dengan cara bareboat charter, time charter, dan freight based dengan pihak vendor. Jenis kapal yang akan digunakan harus mempertimbangkan beberapa hal, seperti: kapasitas kapal dan Dead Weighted Tonnase (DWT) kapal. Penggambaran Causal Loop Diagram penelitian ini ditunjukkan pada gambar berikut:

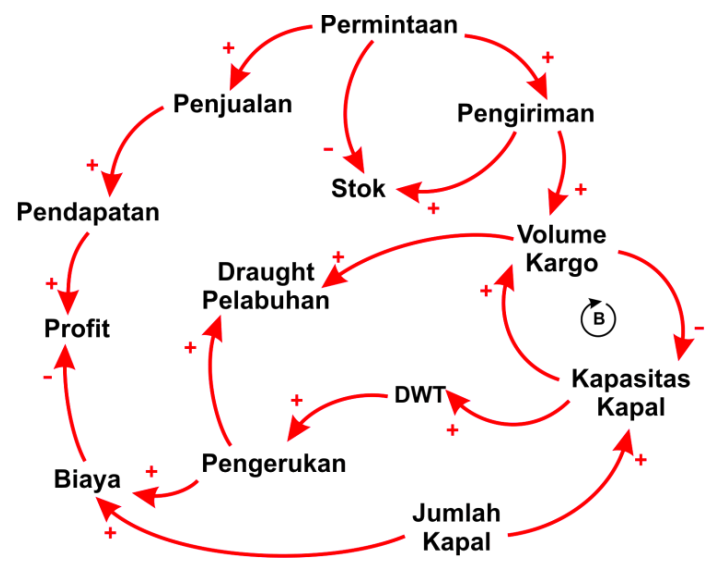

CLD Investasi Kapal

\section{Kapasitas produksi Silo Pelabuhan (ton)}

Silo pelabuhan merupakan sarana penampungan dan pendistribusian semen curah sebelum dikirimkan ke beberapa Packing Plant yang terletak di luar pulau. Kapasitas produksi per tahun sebesar 1.500.000. Semen curah didistribusikan ke Packing Plant tujuan sebelum mencapai reorder point (R). Persamaan yang digunakan adalah sebagai berikut:

$$
R=S S+\bar{x}
$$

Dengan Safety Stock

$$
S S=Z \sigma \sqrt{L T}
$$


Fungsi (1) menyatakan reorder poin yang dipengaruhi oleh Safety Stock dinyatakan pada persamaan (2). Nilai $\bar{x}$ merupakan mean demand, nilai $Z$ adalah safety factor, $\sigma$ merupakan standar deviasi demand, dan LT adalah lead time.

Semen didistribusikan dari Silo Pelabuhan ke Packing Plant sesuai dengan karakteristik pelabuhan tujuan (draught pelabuhan) dan kapasitas Packing Plant.

\section{Kapasitas Packing Plant (ton)}

Terdapat delapan PP tujuan yang memiliki kapasitas berbeda-beda, seperti yang ditunjukkan pada tabel berikut:

Kapasitas Silo Packing Plant (Tonasa, 2014)

\begin{tabular}{|l|c|c|c|c|c|c|c|c|}
\hline $\begin{array}{l}\text { Packing } \\
\text { Plant }\end{array}$ & Banjarmasin & Bitung & Bali & Samarinda & Ambon & Palu & Kendari & Mamuju \\
\hline $\begin{array}{l}\text { Kapasitas } \\
\text { (ton) }\end{array}$ & 12.000 & 12.000 & 12.000 & 12.000 & 8.000 & 8.000 & 6.000 & 4.000 \\
\hline
\end{tabular}

Kapal mengangkut semen curah dari Pelabuhan Silo Produksi ke masing-masing Packing Plant dengan memaksimumkan kapasitas (volume) kapal. Tetapi dibatasi oleh kedalaman (draught) pelabuhan tujuan.

\section{Draught Pelabuhan (m)}

Draught pelabuhan merupakan variabel yang berpengaruh untuk menentukan kapasitas kapal yang dapat berlabuh di dermaga. Setiap kapal yang akan berlabuh harus memenuhi kriteria draught pelabuhan Packing Plant tujuan. Berikut tabel draught pelabuhan untuk masing-masing Packing Plant:

Draft Packing Plant Tujuan (Tonasa, 2014)

\begin{tabular}{|l|c|c|c|c|c|c|c|c|}
\hline $\begin{array}{l}\text { Packing } \\
\text { Plant }\end{array}$ & Banjarmasin & Bitung & Bali & Samarinda & Ambon & Palu & Kendari & Mamuju \\
\hline $\begin{array}{l}\text { Draft } \\
(\mathrm{m})\end{array}$ & 5 & 10 & 8 & 5 & 10 & 10 & 6 & 4 \\
\hline
\end{tabular}

\section{Waktu Tempuh Kapal (hari)}

Berdasarkan kapasitasnya, kapal memiliki laju yang berbeda-beda. Sehingga waktu tempuh masingmasing kapal berbeda pula. Jarak antar lokasi (Pelabuhan Produksi dan Packing Plant) juga berbedabeda. Berikut gambar stock and flow diagram untuk waktu tempuh kapal kapasitas 1.000 ton.

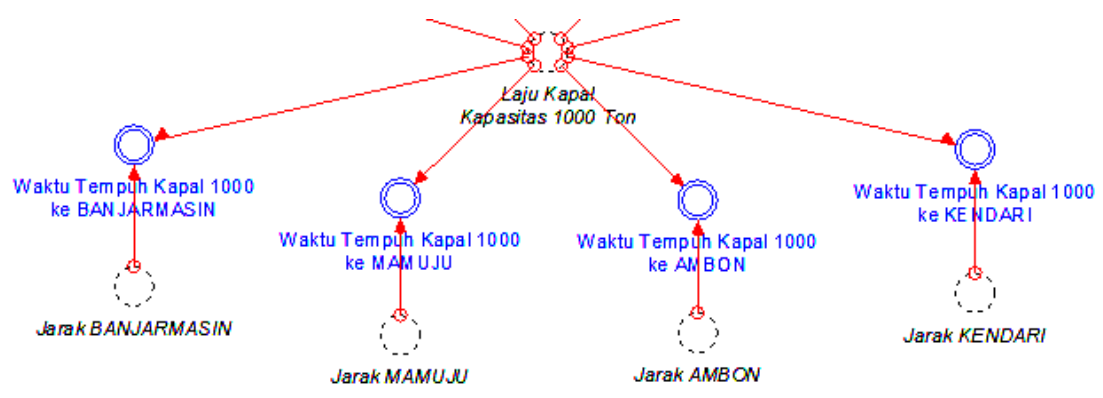

Stock and Flow Diagram Waktu Tempuh Kapal Kapasitas 1.000 Ton

Kapal mengangkut semen curah dengan memaksimumkan kapasitas kapal dan berdasarkan kapasitas Packing Plant. Kapal harus mendistribusikan semen sebelum terjadi stock out di Packing Plant. Sehingga waktu tempuh kapal ke Packing Plant dipengaruhi oleh kapasitas kapal.

\section{Jadwal Kapal}

Kapal melakukan pengiriman ke Packing Plant berdasarkan penjadwalan yang telah dibuat sebelumnya untuk menghindari terjadinya antrian yang lama. Kapal dilayani secara bergantian di silo Pelabuhan Produksi dan silo Packing Plant. Berikut gambar variabel-variabel yang mempengaruhi dalam keputusan penjadwalan kapal. 

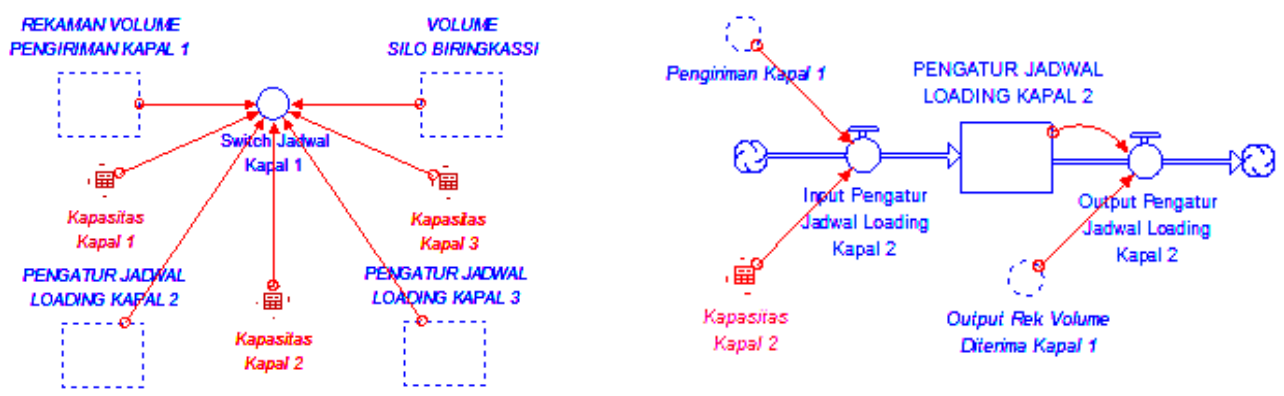

Variabel-Variabel Keputusan Penjadwalan Kapal

\section{Reorder Point dan Order Size (ton)}

Silo Pelabuhan Produksi melakukan pengiriman ke Packing Plant ketika stok di Packing Plant mencapai reorder point. Jumlah pengiriman ke Packing Plant dihitung berdasarkan Persamaan (1). Variabel ini dipengaruhi oleh Persamaan (2). Jadi kapal mengangkut semen ke Packing Plant sebesar reoder point ketika silo Packing Plant mencapai safety stock. Semen curah harus terisi di silo Packing Plant sebelum lead time demand.

\section{Permintaan/Penjualan di Packing Plant (ton)}

Besarnya demand masing-masing Packing Plant berbeda-beda bergantung pada volume penjualan di Packing Plant tersebut. Stok Packing Plant akan berkurang sesuai dengan demand-nya. Demand Packing Plant akan mengalami peningkatan seiring waktu.

\section{Volume Pengiriman Order (ton)}

Silo Pelabuhan Produksi mengirimkan semen curah ke Packing Plant berdasarkan order size dan safety stock. Pengiriman semen juga menyesuaikan dengan kapasitas kapal yang akan memuat semen. Stock semen di Pelabuhan Produksi berkurang seiring adanya pengiriman ke Packing Plant.

\section{Investasi Kapal}

Peningkatan demand di Packing Plant menyebabkan peningkatan kapasitas produksi semen sehingga mempengaruhi distribusi semen dari Silo Pelabuhan Produksi ke Packing Plant. Investasi pengadaan kapal dilakukan untuk memenuhi kebutuhan perusahaan dalam mendistribusikan semen curah. Terdapat dua alternatif dalam investasi kapal dry-bulk carrier, yaitu dengan cara bareboat charter, time charter, dan freight based dengan vendor.

\section{HASIL DAN PEMBAHASAN}

Kapal yang digunakan dipilih berdasarkan dua kriteria, yaitu kapasitas kapal dan biaya investasi kapal. Kapal yang digunakan harus mampu mendistribusikan semen curah dari Silo Pelabuhan Produksi ke Packing Plant dengan memaksimumkan muatan kapal. Selain itu, pengiriman semen juga harus mempertimbangkan besar reorder point dari masing-masing Packing Plant. Pendistribusian semen harus dilakukan sebelum stock di Packing Plant mencapai safety stock agar semua demand dapat terpenuhi.

Kapal yang digunakan harus memenuhi syarat dari draught pelabuhan masing-masing Packing Plant. Sehingga jumlah kapal untuk masing-masing jenisnya (berdasarkan kapasitas) harus diperhitungkan. Jenis kapal yang digunakan untuk mendistribusikan semen terdiri dari tujuh, yaitu: kapal kapasitas 1.000 ton; 3.000 ton; 4.000 ton; 5.000 ton; 6.000 ton; 8.000 ton; dan 12.000 ton. Pada kondisi eksisting PP Ambon, PP Bitung dan PP Palu menggunakan kapal berkapasitas 8.000 ton; PP Bali menggunakan kapal berkapasitas 6.000 ton; PP Kendari menggunakan kapal berkapasitas 5.000 ton; PP Banjarmasin dan PP Samarinda menggunakan kapal berkapasitas 4.000 ton; PP Mamuju menggunakan kapal berkapasitas 3.000 ton dan 1.000 ton. Hasil running Software Stella untuk kondisi eksisting ditunjukkan pada gambar berikut: 


\begin{tabular}{|c|c|c|c|c|}
\hline (u) & KAPASITAS KAPAL & $\nabla$ & & \\
\hline & AMBON.Kapasitas Kapal 1 & 8000 & KENDARI.Kapasitas Kapal 1 & 5000 \\
\hline & AMBON.Kapasitas Kapal 2 & 0 & KENDARI.Kapasitas Kapal 2 & 10 \\
\hline & AMBON.Kapasitas Kapal 3 & 0 & KENDARI.Kapasitas Kapal 3 & 0 \\
\hline & BALI.Kapasitas Kapal 1 & 6000 & MAMUJU.Kapasitas Kapal 1 & 3000 \\
\hline & BALI.Kapasitas Kapal 2 & 6000 & MAMUJU.Kapasitas Kapal 2 & 1000 \\
\hline & BALI.Kapasitas Kapal 3 & 0 & MAMUJU.Kapasitas Kapal 3 & 0 \\
\hline & BANJARMASIN.Kapasitas Kapal 1 & 4000 & PALU.Kapasitas Kapal 1 & 8000 \\
\hline & BANJARMASIN.Kapasitas Kapal 2 & 0 & PALU.Kapasitas Kapal 2 & 0 \\
\hline & BANJARMASIN.Kapasitas Kapal 3 & 0 & PALU.Kapasitas Kapal 3 & lo \\
\hline & BITUNG.Kapasitas Kapal 1 & 8000 & SAMARINDA.Kapasitas Kapal 1 & $\mid 4000$ \\
\hline & BITUNG.Kapasitas Kapal 2 & 8000 & SAMARINDA.Kapasitas Kapal 2 & 4000 \\
\hline & BITUNG.Kapasitas Kapal 3 & 0 & SAMARINDA.Kapasitas Kapal 3 & 4000 \\
\hline
\end{tabular}

Hasil Running Kondisi Eksisting

Berdasarkan hasil running model simulasi didapatkan jumlah kapal yang dapat digunakan untuk mendistribusikan semen dari Silo Produksi ke masing-masing Packing Plant. Jumlah kapal kapasitas 3.000 ton sebanyak 1 (satu) unit, kapal kapasitas 4.000 ton sebanyak 2 (dua) unit, kapal kapasitas 5.000 ton sebanyak 1 (satu) unit, kapal kapasitas 6.000 ton sebanyak 3 (tiga) unit, kapal kapasitas 8.000 ton sebanyak 2 (dua) unit, dan kapal kapasitas 12.000 ton sebanyak 2 (dua) unit. Hasil simulasi tidak memperlihatkan untuk menggunakan kapal kapasitas 1.000 ton, seperti yang ditunjukkan pada tabel berikut:

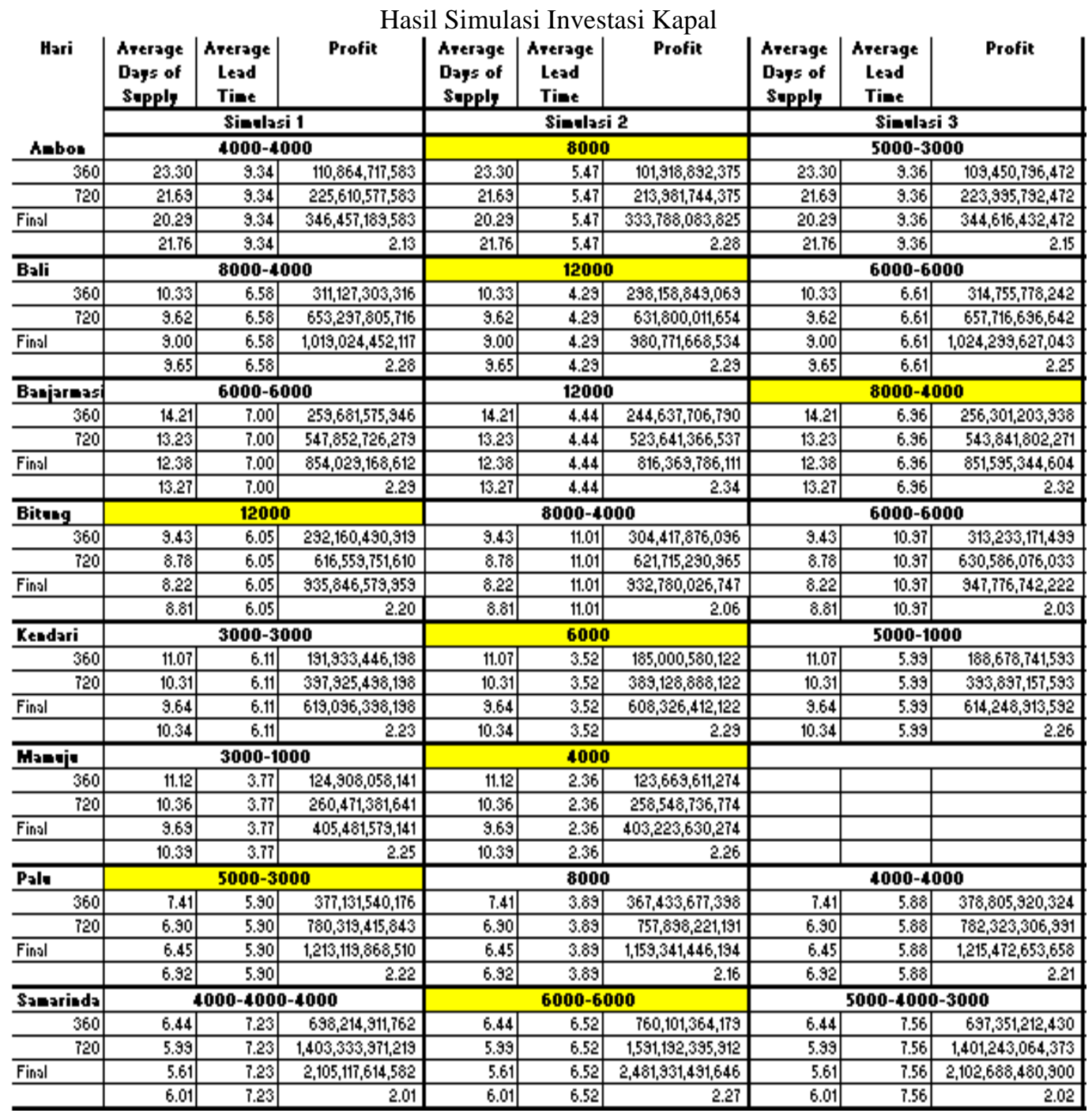


Selanjutnya setelah jumlah kapal diketahui, jenis investasi akan ditentukan. Penyewaan kapal dengan cara bareboat charter, time charter, dan freight based dijadikan sebagai salah satu pilihan dalam menentukan jenis kapal (berdasarkan investasinya). Hasil running simulasi dengan membandingkan profit, diperoleh bahwa penyewaan kapal kapasitas 12.000 ton sebanyak 1 (satu) unit perlu dilakukan. Sehingga semua demand di Packing Plant dapat dipenuhi. Investasi kapal ini dapat meningkatkan profit perusahaan sebesar $2.20 \%$. Jenis penyewaan kapal yang dipilih adalah freight based.

\section{KESIMPULAN}

Berdasarkan hasil simulasi jenis investasi yang dapat dilakukan untuk menghasilkan profit terbesar adalah penyewaan kapal dengan cara freight based. Jumlah kapal yang disewa sebanyak 1 (satu) unit dengan kapasitas 12.000 ton.

Adapun saran yang diberikan untuk penelitian selanjutnya adalah mengembangkan model simulasi ini untuk menyelesaikan permasalahan investasi kendaraan, seperti truk trailer yang digunakan perusahaan semen dalam mendistribusikan semen curahnya melalui jalur darat.

\section{DAFTAR PUSTAKA}

Anggraeni, R. D. \& Suryani, E., 2013. Pemodelan dan Simulasi Perencanaan Permintaan dan Pasokan Menggunakan Metode Sistem Dinamik untuk Mengatasi Kelangkaan Pupuk Wilayah Jawa Timur (Studi Kasus: PT. XYZ). Jurnal Teknik POMITS, I(1), 1-6.

Fan, L. \& Luo, M., 2013. Analyzing Ship Investment Behaviour in Liner Shipping. Maritime Policy \& Management: The Flagship Journal of International Shipping and Port Research, XL(6), pp. 511-533.

Fortunella, A., Tama, I. P. \& Eunike, A., 2012. Simulation Model Of Production System With System Dynamic To Support Production Capacity Planning. Jurnal Rekayasa Dan Manajemen Sistem Industri, III(2), 256-267.

Georgiadis, P., 2013. An Integrated System Dynamics Model for Strategic Capacity Planning in Closedloop Recycling Network: A dynamic analysis for the paper industry. Simulation Modelling Practice and Theory, XXXII, pp. 116-137.

Jin, Y., 2008. Investment in Container Ships for The Yangtze River: A System Dynamics Model, s.l.: IEEE.

Park, S.-i., Wang, Y., Yeo, G.-t. \& Ng, A. K. Y., 2014. System Dynamics Modeling for Determining Optimal Ship Sizes and Types in Coastal Liner Services. The Asian Journal of Shipping and Logistics, $X X X(1), 031-050$.

Sasmito, H. G., 2014. Kajian Perbandingan Biaya Kirim/Ton dengan Sistem Sewa Kapal Time Charter dan Voyage Charter, Surabaya: Jurusan Teknik Industri, Institut Teknologi Sepuluh Nopember.

Steffensen, M.-A., 2012. Maritime Fleet Size and Mix Problems: An Optimization Based Model Approach. Norwegian University of Science and Technology.

Sterman, J. D., 2000. Business Dynamics: System Thinking and Modeling for a Complex Wordl. New York: McGraw Hill.

Tonasa, P. S., 2014. PT. Semen Tonasa: Annual Report 2013, Pangkep: s.n. 